\title{
Coupled thermoelastic analysis of thick-walled pressurized cylinders
}

\author{
Begüm Kanlıkama, Ayşegül Abuşoğlu, İbrahim H. Güzelbey \\ Department of Mechanical Engineering, University of Gaziantep, Gaziantep, Turkey \\ Email address: \\ kanlikama@gantep.edu.tr(B. Kanlıkama), ayabusoglu@gantep.edu.tr(A. Abuşoğlu), guzelbeyih@gantep.edu.tr(İ. H. Güzelbey)
}

To cite this article:

Begüm Kanlıkama, Ayşegül Abuşoğlu, İbrahim H. Güzelbey. Coupled Thermoelastic Analysis of Thick-Walled Pressurized Cylinders. International Journal of Energy and Power Engineering. Vol. 2, No. 2, 2013, pp.60-68. doi: 10.11648/j.ijepe.20130202.15

\begin{abstract}
In the present study, the coupled thermoelastic analysis was carried out for determining the temperature, radial displacement, and radial and circumferential stress distributions of a classical cylinder, and later a reactor pressure vessel exposed to an inner moderator pressure and thermal loads. For the solution, a critical region is analyzed to imitate the effect of the outlet nozzles of the reactor pressure vessel. In order to certify our computational code, the temperature, radial displacement, radial stress, and circumferential stress distributions were also calculated using finite element (FE) method. It was concluded that the analytical results were in good agreement with the computational ones for the classic cylinder. The effect of thermomechanical loads on the temperature, displacement, and stress distributions was discussed in detail. This presented analysis proposes satisfactory results to design reactor pressure vessels.
\end{abstract}

Keywords: Coupled Thermoelasticity, Thick-Walled Cylinder, Reactor Pressure Vessel, Outlet Nozzles

\section{Introduction}

Reactor pressure vessels often have a combination of high temperatures together with high pressures, sometimes in cases of highly radioactive materials. The pressure vessels have to be designed carefully in order to deal with the operating pressure and temperature. The reactor pressure vessel provides hot reactor coolant fluid to each steam generator through a section of piping called the hot legs. This hot reactor coolant fluid exits the reactor pressure vessel shell via the hot legs or outlet nozzles. Thick-walled cylindrical pressure vessels have a wide spectrum of applications in various industries, likewise high pressure reactor in extreme conditions, due to their high corrosion resistance and high safety performance.

Zhang et al. [1] derived an analytical solution for determining the stress distribution of a multilayered composite pressure vessel subjected to an internal fluid pressure and a thermal load. The stress distribution of the pressure vessel was computed using FE method. Ali, Ghosh, and Alam [2] investigated the effect of autofrettage process in strain hardened thick-walled pressure vessels theoretically by FE modeling. Wang and Ding [3] obtained the thermoelastic dynamic solution of a multilayered orthotropic hollow cylinder in the state of axisymmetric plane strain. Atefi and Mahmoudi [4] offered an analytical solution for obtaining thermal stresses in a pipe caused by periodic time varying of temperature of medium fluid. Jabbari, Sohrabpour, and Eslami [5] developed a general analysis of one-dimensional steady-state thermal stresses in a hollow thick cylinder made of functionally graded material. Shao, Wang, and Ang [6] carried out thermomechanical analysis of functionally graded hollow cylinder subjected to axisymmetric mechanical and transient thermal loads. Nevertheless, none of these studies took the effect of the four outlet nozzles of a reactor vessel into consideration. In fact, the outlet nozzles are in direct fluid contact with cylindrical wall of the cylindrical reactor vessel. In this manner, it is essential to examine the effect of outlet nozzles in designing reactor pressure vessels.

It is hard to approximate convection and radiation effects in vessel wall solids of complicated shape as coupled thermomechanical analyses are needed in areas of high strain gradients. The uncoupled thermoelasticity behavior of a thick-walled cylinder of finite length with internal sources of radiation whose temperature was changing linearly was studied by Lamba and Khobragade [7]. The stresses and the temperature distribution for uncoupled thermoelasticity problem with radiative boundary conditions were obtained. Bessel functions of infinite series can be used in order to obtain the solutions. Generalized closed-form solutions are obtained by Tutuncu and Ozturk 
[8] for spherical and cylindrical pressure vessels with changing elastic properties obeying a power law through the vessel wall thickness which resulted in Euler-Cauchy equations. The transient behavior of a quasi-static coupled thermoelastic case for annular cylinders was also studied under different boundary conditions by Ghosn and Sabbaghian [9], Hung, Chen, and Lee [10], and Lee, Chen, and Hung [11]. Additionally, Santos, Soares, Soares, and Reddy [12] developed a semi-analytical axisymmetric finite element model using the three-dimensional linear elasticity theory. The heat conduction and the thermoelastic equations for a functionally graded axisymmetric cylinder subjected to thermal loading are solved by Reddy and Chin [13]. Nevertheless, many researches were only carried on by means of theoretical techniques just as finite difference method or Laplace transform. Results without any proof are almost unpersuasive. As a result, efforts for studies must be devoted to determine the steady-state stress distribution of a classical cylinder or nuclear reactor pressure vessel under a uniform thermomechanical load. Later, the developed code, the commercial FE software and whenever available analytical solution should be used for validation.

In spite of the fact that the thermoelasticity theory has been broadly put into use to solve engineering problems in the field of pressure vessels, there is no open literature on the determination of thermomechanical stresses of a nuclear reactor pressure vessel dealing with the effect of its outlet nozzles. In the present study, the focus is to determine the steady-state temperature, radial displacement, and stress distributions of a nuclear reactor pressure vessel under a uniform thermomechanical load. An internal pressure is introduced to imitate the influence of the coolant fluid of the reactor pressure vessel. To certify the solution from our computational code, a finite element model of a reactor pressure vessel cross-section is also established. The influence of outlet nozzles and thermal loads on the temperature, displacement, and stress distributions is considered in detail. In this manner, the introduced numerical solution supplies a satisfactory result in order to design nuclear reactor pressure vessels.

\section{Governing Equations}

\subsection{Linearized Field Equations for Elastic Materials}

The developed finite element equations are based upon displacement finite element methods so it requires starting from strains and displacements. Hence involving the constitutive relationship, the stresses and forces are being calculated. For this reason, the nonlinear strain tensor will be written based upon Green's strain tensor using the Lagrangian description as follows [14]:

$$
E_{i j}=\frac{1}{2}\left(\frac{\partial u_{i}}{\partial x_{j}}+\frac{\partial u_{j}}{\partial x_{i}}+\frac{\partial u_{\alpha}}{\partial x_{i}} \frac{\partial u_{\alpha}}{\partial x_{j}}\right)
$$

The research is restricted to small strain problems so the nonlinear equation will be reduced to linear equation as Cauchy's infinitesimal strain tensor:

$$
E_{i j}=\frac{1}{2}\left(\frac{\partial u_{i}}{\partial x_{j}}+\frac{\partial u_{j}}{\partial x_{i}}\right)
$$

The coefficient of thermal expansion may be defined as the amount of strain induced by some change in temperature in a solid in stress-free state. Then, the constitutive law (Duhamel Neumann law) can be expressed as,

$$
\sigma_{i j}=C_{i j k l}\left(E_{k l}-\alpha_{k l} \Delta T\right)
$$

Then, the equation for linear momentum balance of linear elastostatics may be given as,

$$
\frac{\partial \sigma_{j i}}{\partial x_{j}}+\rho b_{i}=0
$$

The field equations for isotropic, linear elastic solids may be reduced by eliminating the strain and stress from the governing equations. Then, they can be solved directly for displacement. Therefore, the equation for linear momentum balance can be expressed as,

$$
C_{i j k l} \frac{\partial}{\partial x_{i}}\left(\frac{\partial u_{k}}{\partial x_{l}}-\alpha_{k l} \Delta T\right)+\rho b_{j}=0
$$

The internal forces in terms of displacement components are governed in the following vectorial form:

$$
\mu \nabla^{2} \vec{u}+\frac{\mu}{(1-2 p)} \nabla(\nabla . \vec{u})+\vec{b}-\beta \nabla T=0
$$

\subsection{Thermal Equations}

Expression for the conservation of energy in a solid medium for transfer of heat is governed in vector form by Reddy [15] as:

$$
\begin{gathered}
\frac{\partial}{\partial x}\left(k \frac{\partial T}{\partial x}\right)+\frac{\partial}{\partial y}\left(k \frac{\partial T}{\partial y}\right)+\frac{\partial}{\partial z}\left(k \frac{\partial T}{\partial z}\right)+Q=\rho c \frac{\partial T}{\partial t} \\
\hat{q}=-k \nabla T=-k\left(i \frac{\partial T}{\partial x}+j \frac{\partial T}{\partial y}+k \frac{\partial T}{\partial z}\right)
\end{gathered}
$$

where $k$ is the heat conductivity, $\mathrm{T}(\mathrm{x}, \mathrm{y}, \mathrm{z})$ is the scalar temperature field, $Q$ is the rate of internal heat generation per unit volume, $\rho$ is the mass density, $C$ is the specific heat per unit mass at constant volume and $\hat{q}$ is the heat flux vector. The first equation is the general threedimensional heat conduction equation and the second equation is the general statement of the conduction rate equation (Fourier's law).

Conservation of thermal and mechanical energy in an 
isotropic homogeneous solid for fully coupling of the thermal and elasticity processes is governed by the following differential equation:

$$
k\left(\frac{\partial^{2} T}{\partial x^{2}}+\frac{\partial^{2} T}{\partial y^{2}}+\frac{\partial^{2} T}{\partial z^{2}}\right)=T \frac{\partial}{\partial t}(\beta E)+\rho c \dot{T}-Q
$$

where $E$ is the volume strain, and the coupled thermoelastic deformation is dependent on time. The first term on the right side of the equation accounts for the mechanical energy of the coupled thermoelastic process. This term corresponding to mechanical energy is neglected for the uncoupled thermoelastic process in (7). A small change in temperature compared to the ambient absolute temperature is assumed in this case.

For the convective boundary, if a region in the boundary must be in touch with the fluid which has a temperature of $T_{f}$ outside the thermal boundary layer. The normal component of the heat flux vector can be given as:

$$
\hat{q}_{n}=-k \frac{\partial T}{\partial n}=h\left(T_{b}-T_{f}\right)
$$

where $h$ is the convection heat transfer coefficient.

For the radiative boundary, a body which has a temperature of $T_{b}$ subjected to a heat source at temperature $T_{s}$ may transfer heat from or to outside, by thermal radiation.

$$
\hat{q}_{\text {rad }}=\frac{q}{A}=\varepsilon E_{b}\left(T_{b}\right)-\alpha G=\varepsilon \sigma_{B}\left(T_{b}^{4}-T_{s}^{4}\right)
$$

where $\mathcal{E}$ is the emissivity and $\sigma_{B}$ is the StefanBoltzmann constant and it's numerical value is $5.676 \times 10^{-8} \mathrm{~W} / \mathrm{m}^{2} \mathrm{~K}^{-4}$. The boundary condition can be given as:

$$
k \frac{\partial T}{\partial n}+\varepsilon \sigma_{B}\left(T_{b}^{4}-T_{s}^{4}\right)=0
$$

A body can possess multimode heat transfer conditions. The boundary condition for both convective and radiative conditions can be written as:

$$
k \frac{\partial T}{\partial n}+h\left(T_{b}-T_{f}\right)+\varepsilon \sigma_{B}\left(T_{b}^{4}-T_{s}^{4}\right)=0
$$

The thermal analysis is conducted by imposing constant surface temperatures at the edge surfaces. There is no variation of temperature is assumed to occur in the models.

\subsection{Analytical Solution of Thick Pressurized Cylinder under Thermal Loads}

Three principal stresses are generated by internal pressure: a hoop stress $\sigma_{t}$, a radial stress $\sigma_{r}$, and a longitudinal stress $\sigma_{z}$. The latter is due to the thrust of pressure on the heads of the cylinder. The values of the stresses $\sigma_{t}$ and $\sigma_{r}$ are not constant through the cylinder wall, whereas $\sigma_{z}$ is in fact constant [16]. In this manner, we analyzed a two-dimensional cross-section of the hollow cylinder.

A usual thick-walled cylinder of internal and external radii of $r_{i}$ and $r_{o}$, respectively, and internal and external pressures of $p_{i}$ and $p_{o}$, respectively. Equations for the radial and circumferential stresses in a thick-walled cylinder were introduced by Lamé. In generalized form, radial and circumferential stress components are [17]:

$$
\begin{aligned}
& \sigma_{r}=p_{i} \frac{r_{i}^{2}\left(r^{2}-r_{o}^{2}\right)}{r^{2}\left(r_{o}^{2}-r_{i}^{2}\right)}-p_{o} \frac{r_{o}^{2}\left(r^{2}-r_{i}^{2}\right)}{r^{2}\left(r_{o}^{2}-r_{i}^{2}\right)} \\
& \sigma_{r}=p_{i} \frac{r_{i}^{2}\left(r^{2}+r_{o}^{2}\right)}{r^{2}\left(r_{o}^{2}-r_{i}^{2}\right)}-p_{o} \frac{r_{o}^{2}\left(r^{2}+r_{i}^{2}\right)}{r^{2}\left(r_{o}^{2}-r_{i}^{2}\right)}
\end{aligned}
$$

For the next computations, only an inner pressure is assumed on the thick-walled cylinder, which means that $p_{o}=0$. Likewise, the above equations can be developed for an entirely external pressure or a pressure gradient over the whole cylinder.

For a purely internal pressure $\left(p_{i}=p\right),(14)$ reduce to:

$$
\begin{aligned}
& \sigma_{r}=p \frac{r_{i}^{2}\left(r^{2}-r_{o}^{2}\right)}{r^{2}\left(r_{o}^{2}-r_{i}^{2}\right)} \\
& \sigma_{r}=p \frac{r_{i}^{2}\left(r^{2}+r_{o}^{2}\right)}{r^{2}\left(r_{o}^{2}-r_{i}^{2}\right)}
\end{aligned}
$$

Physical conditions that include radiation together with conduction and convection heat transfer modes are quite common. Physical examples contain automobile radiators, heat transfer in the reactor vessel of nuclear power plants and in the incinerator of boilers. The general energy equations are evolved into more complicated ones when they consist of both temperature gradient coming from convection heat transfer mode and temperature derivatives coming from conduction heat transfer mode. For that reason, there is not any classical method of solution, but numerical techniques. When the outer wall of the thickwalled cylinder is exposed to a uniform temperature $T_{o}$, the inner wall is held in contact with the coolant fluid, and exposed to radiation by a radiation source within its inner walls, the magnitude of its temperature at the inner wall is given by:

$$
T=T_{i}+\left(T_{o}-T_{i}\right) \frac{\log \frac{r}{r_{i}}}{\log \frac{r_{o}}{r_{i}}}
$$

where $r_{i}$ denotes the inner radius, and $r_{o}$ is the outer radius of the cylinder [18].

For the elastic domain the stresses, strains, and displacements resulting from a combination of pressure and thermal loads may be found by simple superposition. For 
the plane strain case, the radial stress is a combination of the equations for pressure and thermal cases [19].

$$
\begin{gathered}
\sigma_{r}=p \frac{r_{i}^{2}\left(r^{2}-r_{o}^{2}\right)}{r^{2}\left(r_{o}^{2}-r_{i}^{2}\right)}+\frac{E \alpha\left(T_{i}-T_{o}\right)}{2 \ln \left(\frac{r_{o}}{r_{i}}\right)(1-v)} \ldots \\
{\left[\frac{r_{i}^{2}}{r_{o}^{2}-r_{i}^{2}}\left(\frac{r_{o}^{2}}{r^{2}}-1\right) \ln \left(\frac{r_{o}}{r_{i}}\right)-\ln \left(\frac{r_{o}}{r}\right)\right]} \\
\sigma_{t}=p \frac{r_{i}^{2}\left(r^{2}+r_{o}^{2}\right)}{r^{2}\left(r_{o}^{2}-r_{i}^{2}\right)}+\frac{E \alpha\left(T_{i}-T_{o}\right)}{2 \ln \left(\frac{r_{o}}{r_{i}}\right)(1-v)} \ldots \\
\left.\left.u_{r}=r \frac{p(1+v)}{E} \frac{r_{i}^{2}}{r_{o}^{2}-r_{i}^{2}}\left(\frac{r^{2}+r_{o}^{2}}{r^{2}}-2 v\right)+\ldots r \frac{r_{i}^{2}}{r^{2}}\right) \ln \left(\frac{r_{o}}{r_{i}}\right)\right] \\
{\left[1-\ln \left(\frac{r_{o}}{r}\right)-\frac{r_{i}^{2}}{r_{o}^{2}-r_{i}^{2}}\left(1+T_{o}\right)\right.} \\
{\left[\begin{array}{l}
(v+1) \ln \left(\frac{r_{o}}{r}\right)+\left(1-v^{2}\right)-\left(\frac{r_{i}^{2}}{r_{o}^{2}-r_{i}^{2}}\right) \ldots \\
{\left[\begin{array}{l}
(1+v) \frac{r_{o}^{2}}{r^{2}}+(1-v)-2 v^{2} \\
r_{i}
\end{array}\right]+\ldots} \\
\ln \left(\frac{r_{o}}{r_{i}}\right)
\end{array}\right]} \\
r(1+v) \alpha\left(T_{o}-T_{0}\right)
\end{gathered}
$$

\section{Numerical Solution and Finite Element Validation}

\subsection{Finite Element Modeling of a Thick-Walled Cylinder}

To certify the solutions from our computational code, a thermomechanical finite element modeling of a typical thick-walled cylinder was built. Due to the axisymmetry characteristic of the thick-walled cylinder and its boundary conditions, a one-fourth of the geometrical model (Fig. 1) was built with the 8-noded thermal elements PLANE77 with the element behavior of plane strain and the 8-noded plane elements PLANE183 with the element behavior of plane strain by means of the finite element software ANSYS. Zero-displacement in $\mathrm{x}$-direction is applied for the $\mathrm{x}=0$ line of the geometrical model and zero-displacement in $\mathrm{y}$-direction is applied for the $\mathrm{y}=0$ line of the geometrical model. The numbers of elements and nodes were 480 and 1529 , respectively.

The inside radius of the typical thick-walled cylinder was $0.1 \mathrm{~m}$, whereas its outside radius is $0.2 \mathrm{~m}$. The internal flowing fluid pressure was $15.7 \mathrm{MPa}$, and there is not any applied pressure externally. The outer temperature was $232.7{ }^{\circ} \mathrm{C}$, the inner fluid temperature was $325^{\circ} \mathrm{C}$, and the temperature from the radiation source which is subjected internally to the cylinder was $1573 \mathrm{~K}$.

\subsection{Finite Element Modeling of a Reactor Pressure Vessel}

A thermomechanical finite element modeling of the cross-section of the nozzle region of a reactor pressure vessel was built in order to certify the solutions from our computational code. Due to the axisymmetry characteristic of the nozzle region cross-section and its boundary conditions, a one-fourth of the geometrical model (Fig. 2) was built with the 8-noded thermal elements PLANE77 with the element behavior of plane strain and the 8-noded plane elements PLANE183 with the element behavior of plane strain by means of the finite element software ANSYS like in the first case. Again, zero-displacement in $\mathrm{x}$-direction is applied for the $\mathrm{x}=0$ line of the geometrical model and zero-displacement in y-direction is applied for the $\mathrm{y}=0$ line of the geometrical model. The numbers of elements and nodes were 336 and 1185, respectively. A cross-section at A-A (Fig. 3) of the pressure vessel is shown in Fig. 4.

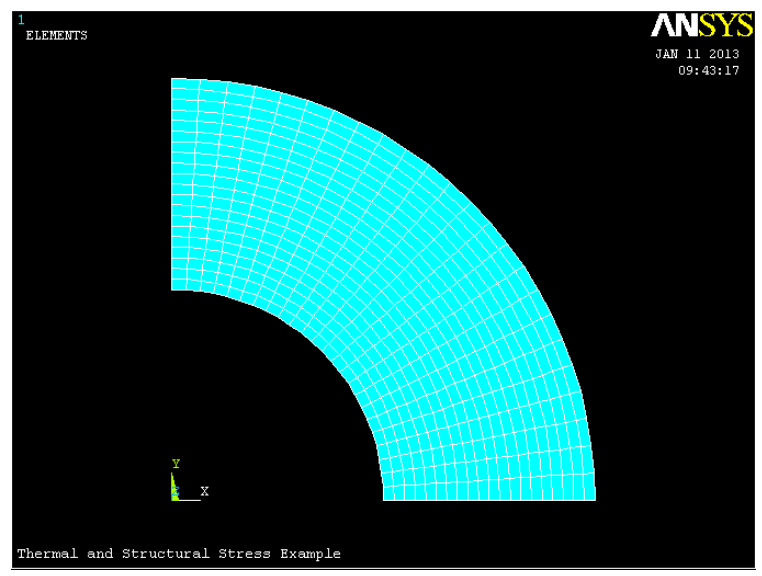

Figure 1. Finite element mesh for the cylinder consisting of 8-noded quadrilateral elements.

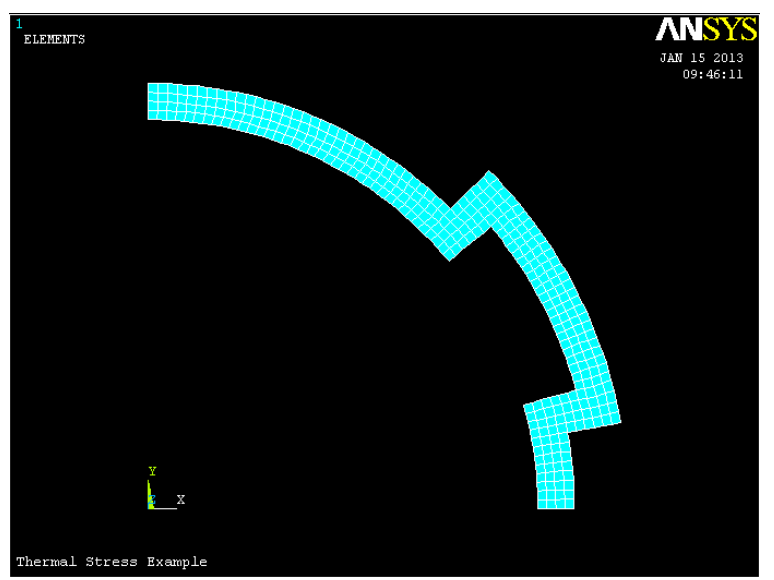

Figure 2. Finite element mesh for the nozzle region cross-section consisting of 8-noded quadrilateral elements.

The inside radius of the nozzle region cross-section was $2.116 \mathrm{~m}$, whereas its outside radius is $2.3135 \mathrm{~m}$. Applied structural and thermal boundary conditions was the same as the ones in the first case. The internal flowing fluid pressure was $15.7 \mathrm{MPa}$, and there is not any applied 
pressure externally. The outer temperature was $232.7{ }^{\circ} \mathrm{C}$, the inner fluid temperature was $325^{\circ} \mathrm{C}$, and the temperature from the radiation source which is subjected internally to the cylinder was $1573 \mathrm{~K}$.

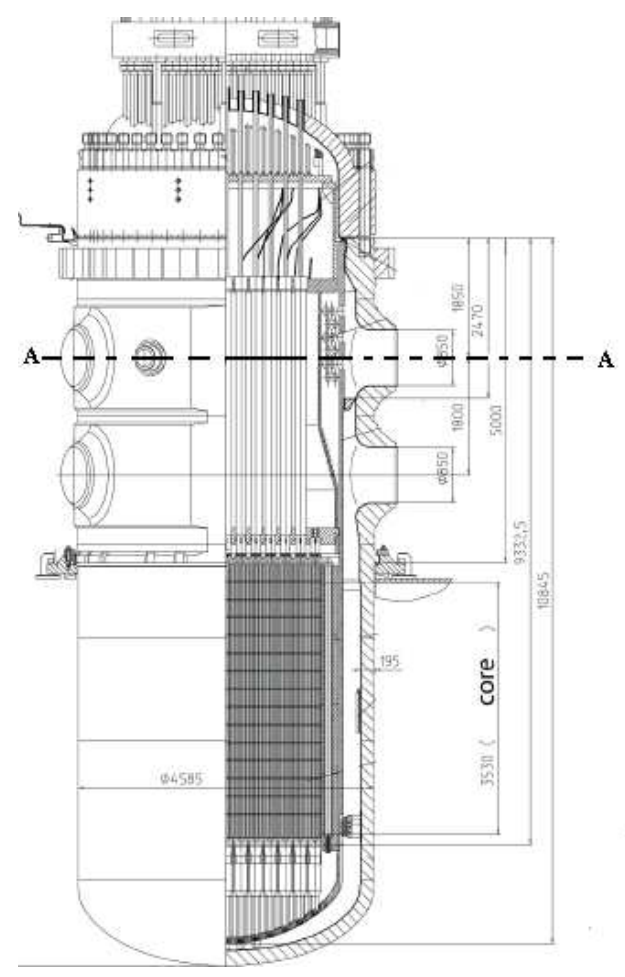

Figure 3. Reactor vessel [20].

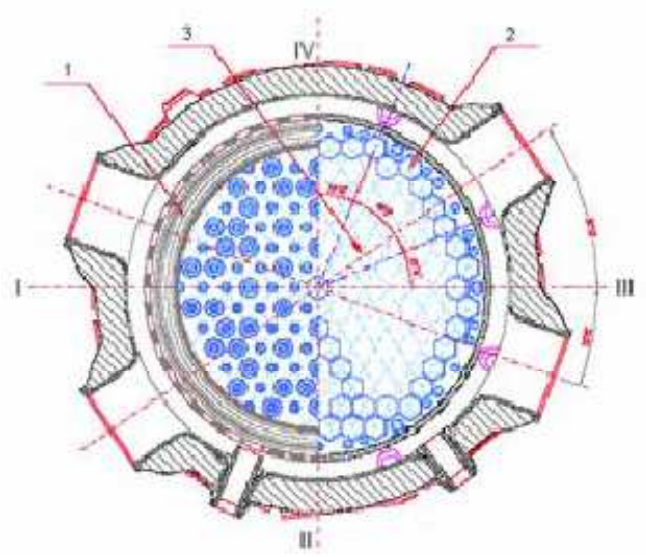

Figure 4. Position of the four nozzles [21].

Some of the parameters of reactor pressure vessel are as follows:

- Inner diameter of the cylindrical shell is $4232 \mathrm{~mm}$.

- Wall thickness of cylindrical shell is $197.5 \mathrm{~mm}$.

The thermomechanical parameters of each case are listed in Table 1. The thermomechanical properties for the case of reactor vessel were adopted from reference [20].

The thermal-stress analysis was carried out using the coupled-field method [22] in order to compute the coupled thermomechanical stresses of the nuclear reactor pressure vessel. The basic solution procedure for the coupled-field method was carried out as:

- The thermal problem was defined, and the temperature boundary conditions were inputted.

- The thermal problem is solved and then the temperature distribution is calculated.

- $\quad$ PREP7 is returned and the database is modified. The element types were switched from the thermal element PLANE77 to its corresponding mechanical element PLANE183.

- Additional material properties and structural boundary conditions were specified. The pressure due to internally flowing fluid was imposed on the internal surface of the finite element model of the reactor pressure vessel.

- The temperatures were read from the thermal results file, and the thermal stresses were obtained.

- The structural problem is solved, and the stresses $\left(\sigma_{r}, \sigma_{t}\right)$ were determined.

Table 1. Material properties

\begin{tabular}{c|cc}
\hline Cases & Thick-walled cylinder & Reactor pressure vessel \\
\hline $\begin{array}{c}\text { Young's } \\
\text { Modulus (Pa) }\end{array}$ & $2.09 \times 10^{11}$ & $2.0577275 \times 10^{11}$ \\
$\begin{array}{c}\text { Poisson's Ratio } \\
\text { Density }\end{array}$ & 0.3 & 0.3 \\
$\left(\mathrm{~kg} \cdot \mathrm{m}^{-3}\right)$ & 7900 & 7850 \\
Heat & & \\
$\begin{array}{c}\text { Conductivity } \\
\left(\mathrm{W} / \mathrm{m}^{\circ} \mathrm{C}\right)\end{array}$ & 48 & 48 \\
Thermal & & \\
Expansion \\
Coefficient \\
$(1 / \mathrm{K})$
\end{tabular}

\subsection{Results and Discussion}

The temperature, radial displacement, radial stress, and circumferential stress that are determined from our computational code and the finite element method are shown in Fig. 5, Fig. 6, Fig. 7, and Fig. 8, respectively. In these diagrams, the parallelogram symbol designates the results from our computational code along the cross-section, and the square symbol designates the results from the finite element method along the cross-section. According to the diagrams, it can be detected that the solution from our computational code agrees closely with the finite element result at the cross-section. Due to the complicatedness in the shape of the pressure vessel cross-section, solely solutions from our computational code and finite element method of temperature, displacement, radial stress, and circumferential stresses were shown in this study.

Poworoznek [19] developed an analytical solution for linear elastic hollow cylinder subjected to a uniform pressure on its inside surfaces by taking thermal load also into consideration. In this particular study, the algorithm was applied in order to calculate the radial stresses. The result from Poworoznek's solution is depicted for comparison. 
Fig. 6 shows the comparison of the radial displacements from the two solutions. It can be seen that the results depict a close agreement with Poworoznek's study when both the pressure and thermal load is applied.

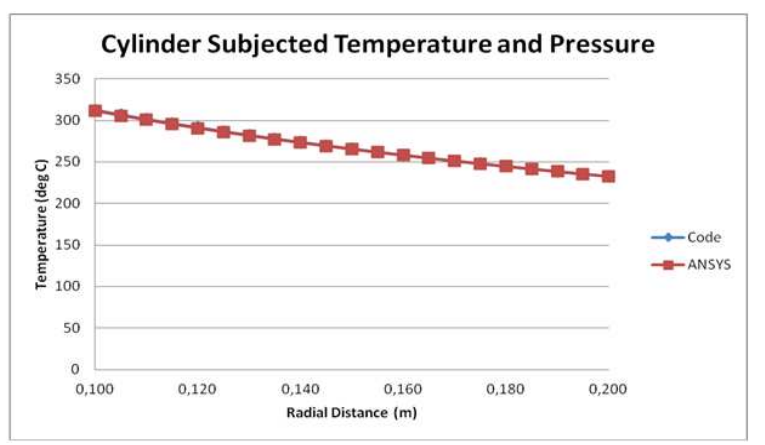

Figure 5. Temperature distributions through the radius of thick-walled cylinder.

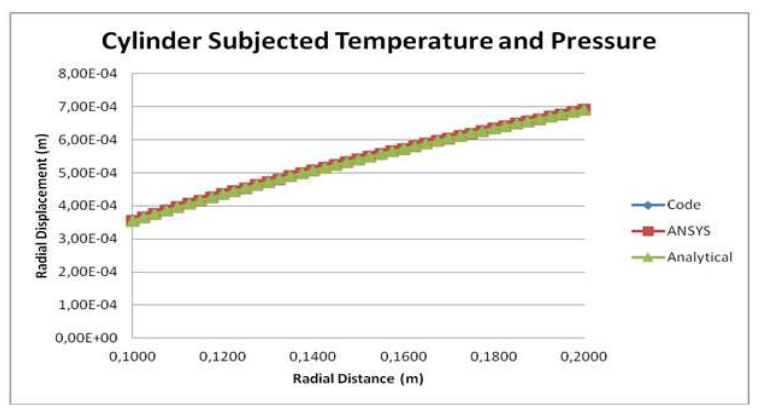

Figure 6. Variation of radial displacement of cylinder with radial distance in different methods.

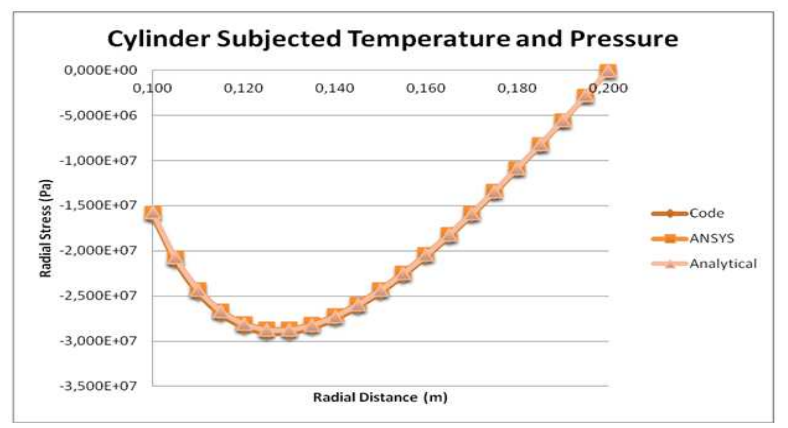

Figure 7. Steady-state radial stresses across the radius of a hollow cylinder subjected to pressure and heating on both internal and outer surface.

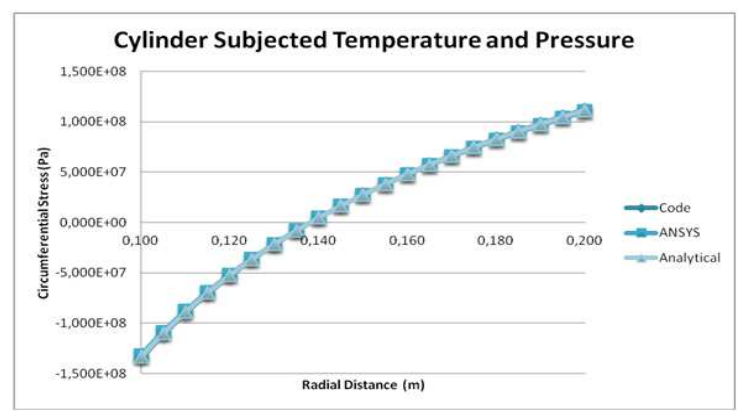

Figure 8. Steady-state hoop stress distributions across the radius of a hollow cylinder subjected to constant heating and pressure.
The geometry of the model included the accurate design of the one inlet nozzle. Although the model is detailed, it also has some simplifications. The four inlet nozzles are not symmetrically located around the reactor core. It is totally included in the provided geometry also. The number of primary circuit loops is 4 . The main operational primary pressure parameter at the core outlet is $15.7 \mathrm{MPa}$.

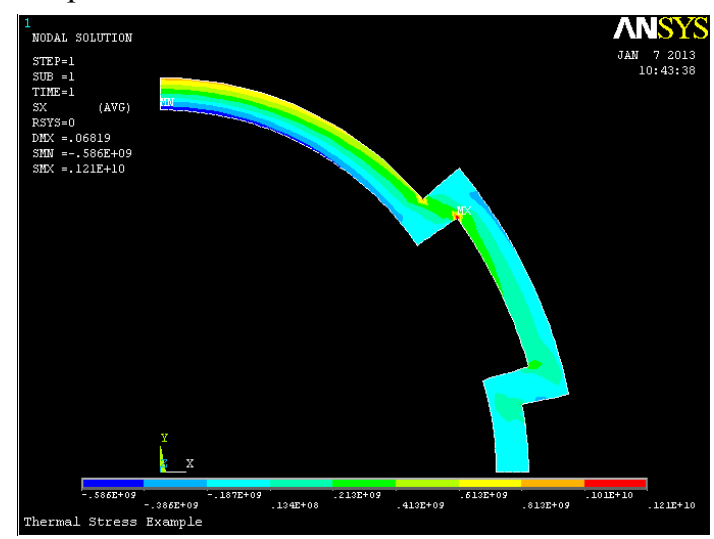

Figure 9. Steady-state radial stress distribution through the nozzle region subjected to constant heating and pressure.

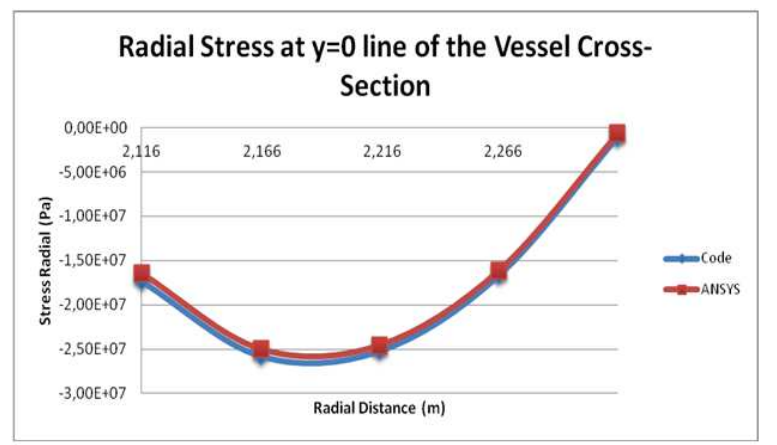

Figure 10. Radial stresses through the radial distance by ANSYS and our code.

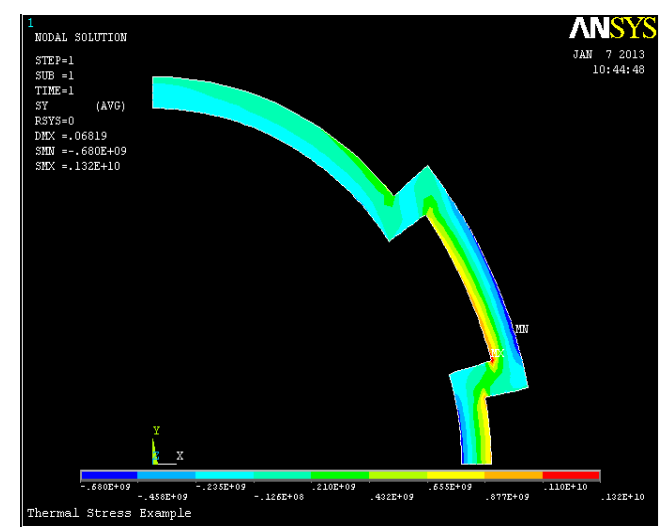

Figure 11. Distribution of hoop stresses through the vessel cross-section by ANSYS and our code.

The reactor pressure vessel has hot leg effects, and in this manner there are changes in the radial stress and circumferential stress distributions at each of the edges of the hot leg. In the internal surface, there is a compressive 
stress state (Fig. 9 and Fig. 11). The radial stress in the inner wall is under compression with a value of approximately $17 \mathrm{MPa}$ (Fig. 10), which is smaller than that of the circumferential stress of nearly $600 \mathrm{MPa}$ (Fig. 12 and Fig. 13). This is an evidence of the importance of the circumferential stress in the reactor vessel case.

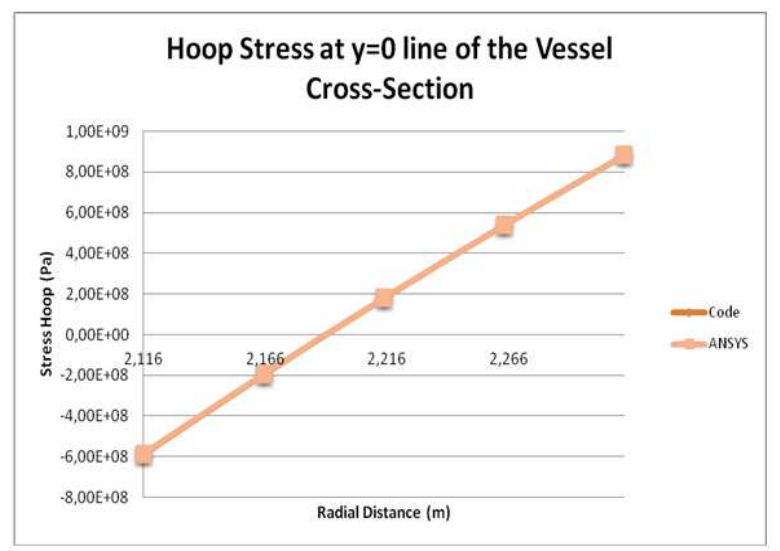

Figure 12. Comparison of hoop stresses through the radial distance by ANSYS and our code.

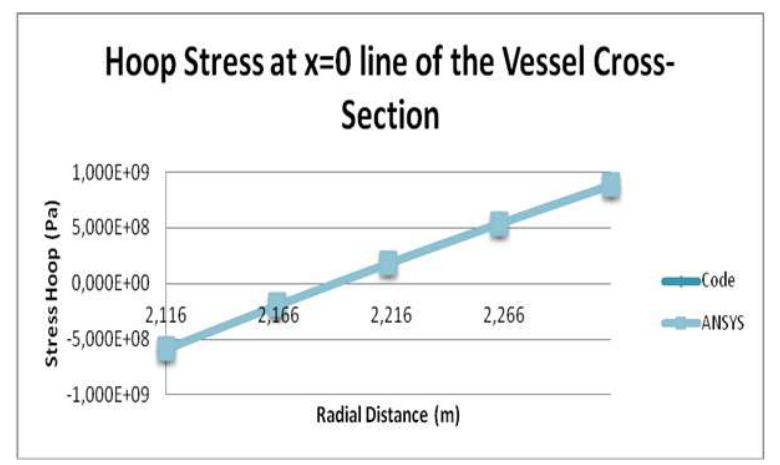

Figure 13. Hoop stresses through $x=0$ edge of the plane strain model.

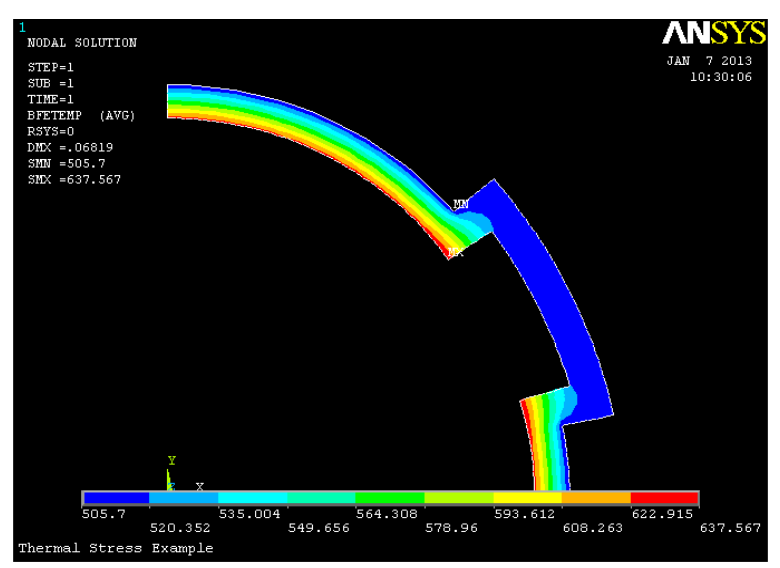

Figure 14. Temperatures through the plane strain model of the vessel cross-section.

Fig. 15 shows the temperatures of each node at the $y=0$ line of the finite element model. Since no plastic deformations were assumed along the pressure vessel, there will be no change in material properties such as thermal expansion coefficient. It can be detected that the temperatures are continuous due to unique material properties along the pressure vessel. Temperature of the hot leg cross-section perpendicular to the flow is greater than the nodal temperature of the thick-walled cylinder. This indicates that temperature plays an important role in determining the radial displacement, radial stress, and circumferential stress. Additionally, it can be also detected from Fig. 14 that temperature has a decreasing trend when the radial distance is going outwards, which agrees with (16).

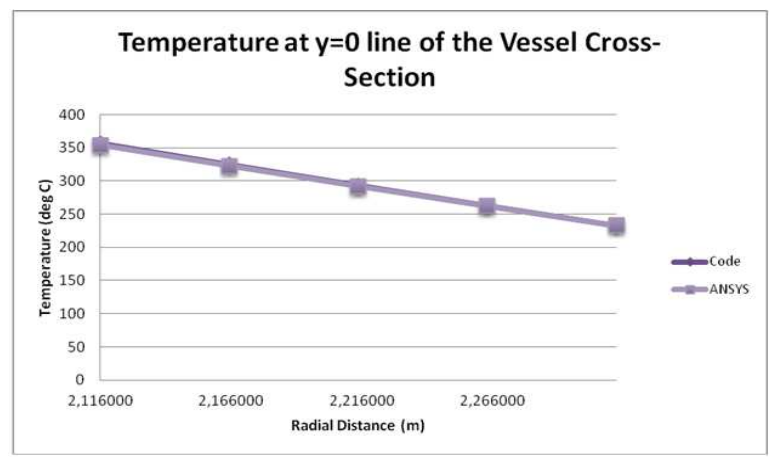

Figure 15. Comparison of temperature distributions through $\mathrm{y}=0$ surface of the model.

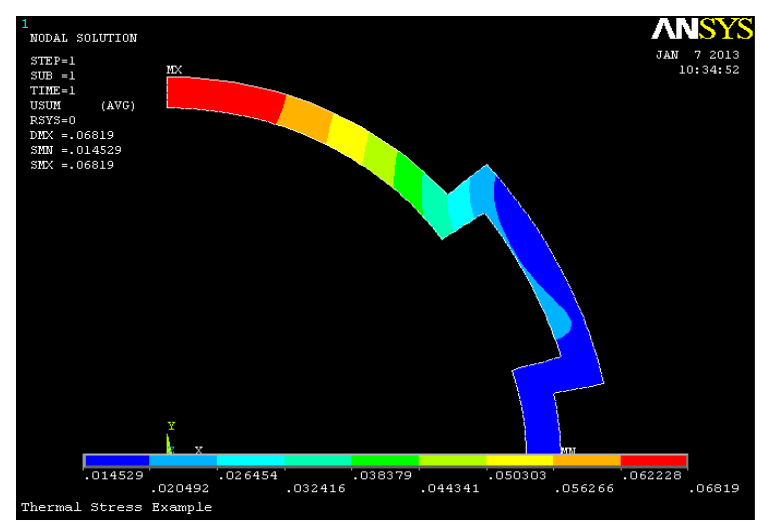

Figure 16. Radial displacement distributions through the finite elements model for plane strain.

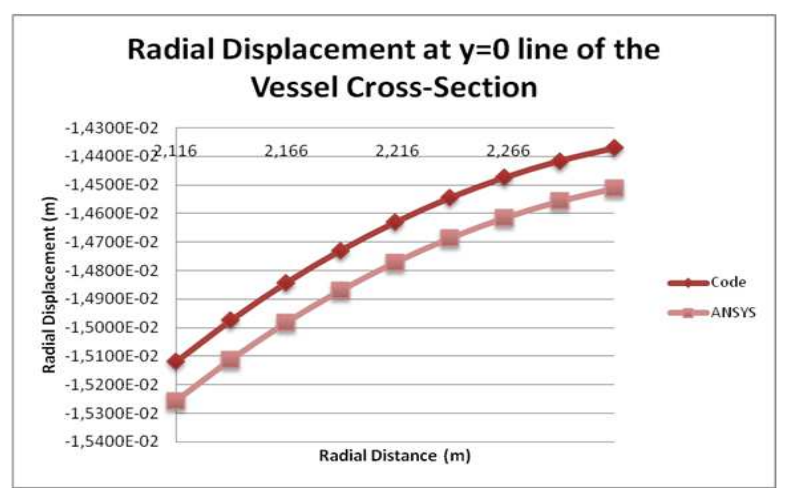

Figure 17. Radial displacement distributions through the thickness of the model. 


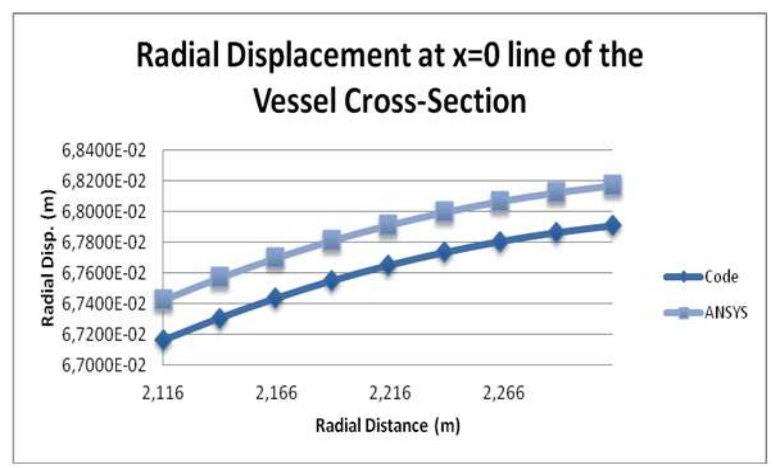

Figure 18. Radial displacement distributions at $\mathrm{x}=0$ surface of the model by ANSYS and our computational code.

Fig. 16, Fig. 17, and Fig. 18 depict the effect of both pressure and thermal loads on the radial displacement stresses in the cylindrical body of the reactor pressure vessel.

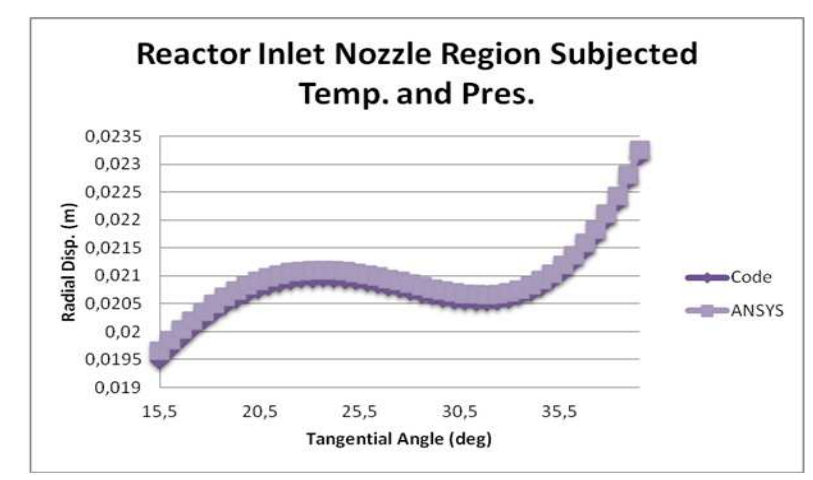

Figure 19. Radial displacements through the inlet nozzle region of the plane strain model.

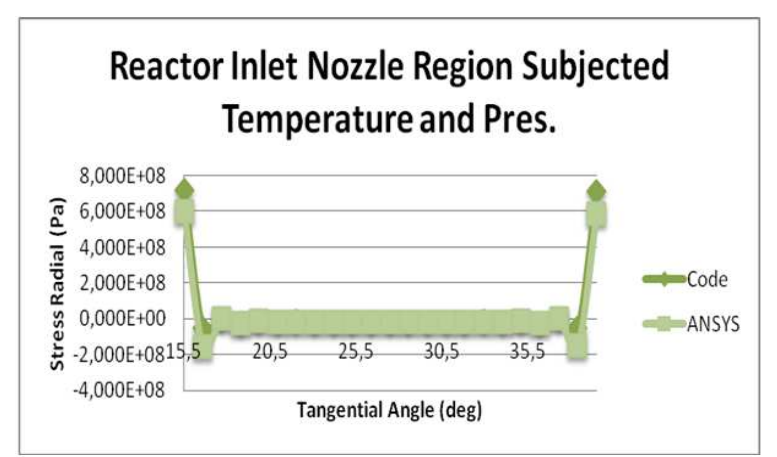

Figure 20. Radial stress distributions through the nozzle flow crosssection of the model by ANSYS and code.

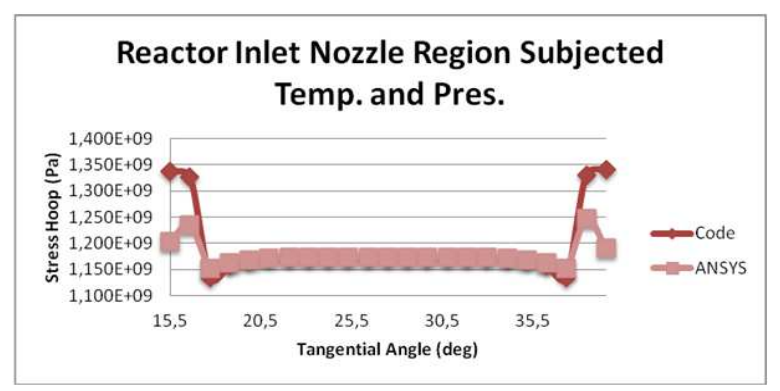

Figure 21. Hoop stresses through the nozzle flow cross-section of the plane strain model by ANSYS and our code.
Also, Fig. 19, Fig. 20, and Fig. 21 demonstrate that the hot leg has an important effect on the radial displacement, radial stress, and circumferential stress distributions.

In order to show the effect of the outlet nozzles on the radial displacement, radial stress, and circumferential stress, corresponding figures along the wall thickness should be compared for reactor pressure vessel and thick-walled cylinder, which means with outlet nozzles and without outlet nozzles. It can be seen that the fluctuations in displacement and stress can be importantly underestimated if the influence of outlet nozzles is neglected.

The coolant fluid pressures were constant with an internal pressure of 15.7 MPa. There is no applied pressure externally to the reactor pressure vessel. Under the conductive, convective, radiative thermal loads, the lower the working temperature, the lower is the magnitude of the stress at the inner and outer surfaces.

\section{Conclusions}

In this study, we attempted to investigate the problem for the mechanical and thermal stresses in a hollow cylinder and an inlet nozzle region of a nuclear reactor pressure vessel due to the two-dimensional steady-state loads. Two potential problems were proposed in order to depict the significant ability of our computational thermoelasticity code for solving the problems of complicated geometries with mechanical and thermal boundary conditions.

Results obtained by our proposed computational thermoelasticity code are in close agreement with the ones obtained by finite element software ANSYS.

\section{References}

[1] Q. Zhang, Z. W. Wang, C. Y. Tang, D. P. Hu, P. Q. Liu, and L. Z. Xia, "Analytical solution of the thermo-mechanical stresses in a multilayered composite pressure vessel considering the influence of the closed ends", International Journal of Pressure Vessels and Piping 98, pp. 102-110, 2012.

[2] A. R. Ali, N. C. Ghosh, and T. E. Alam, "Optimum Design of Pressure Vessel Subjected to Autofrettage Process", World Academy of Science, Engineering and Technology 46, 2010, 667-672.

[3] H. M. Wang, and H. J. Ding, "Transient thermoelastic solution of a multilayered orthotropic hollow cylinder for axisymmetric problems", Journal of Thermal Stresses 27; 2004, pp. 1169-1185.

[4] G. Atefi, and H. Mahmoudi, "Thermal stresses in the wall of pipes caused by periodic change of temperature of medium fluid", The 4th International Meeting of Advances in Thermofluids AIP Conf. Proc. 1440; 2011, pp. 72-89.

[5] M. Jabbari, S. Sohrabpour, and M. R. Eslami, "Mechanical and thermal stresses in a functionally graded hollow cylinder due to radially symmetric loads", International Journal of Pressure Vessels and Piping 79; 2002, pp. 493497. 
[6] Z. S. Shao, T. J. Wang, and K. K. Ang, "Transient thermomechanical analysis of functionally graded hollow circular cylinders", Journal of Thermal Stresses 30:1; 2007, pp. 81104.

[7] N. K. Lamba and N. W. Khobragade, "Uncoupled thermoelastic analysis for a thick cylinder with radiation", Theoretical \& Applied Mechanics Letters 2; 2012, 021005.

[8] N. Tutuncu and M. Ozturk, "Exact solutions for stresses in functionally graded pressure vessels", Compos. Part B. 32; 2001, pp. 683-686.

[9] A. H. Ghosn and M. Sabbaghian, "Quasi-static coupled problems of thermoelasticity for cylindrical regions", Journal of Thermal Stresses 5; 1982, pp. 299-313.

[10] C. I. Hung, C. K. Chen, and Z. Y. Lee, "Thermoelastic transient response of multilayered hollow cylinder with initial interface pressure", Journal of Thermal Stresses 24; 2001, pp. 987-1006.

[11] Z. Y. Lee, C. K. Chen, and C. I. Hung, "Transient thermal stress analysis of multilayered hollow cylinder", Acta Mechanica 151; 2001, pp. 75-88.

[12] H. Santos, C. M. M. Soares, C. A. M. Soares, and J. N. Reddy, "A semi-analytical finite element model for the analysis of cylindrical shells made of functionally graded materials under thermal shock", Composite Structures 86; 2008, pp. 10-21.
[13] J. N. Reddy and C. D. Chin, "Thermomechanical analysis of functionally graded cylinders and plates", Journal of Thermal Stresses 21(6); 1998, pp. 593-626.

[14] Y. C. Fung, "Foundations of solid mechanics", Prentice-Hall, Inc., Englewood Cliffs, New Jersey, 1965.

[15] J. N. Reddy, "An introduction to continuum mechanics with applications”, New York: Cambridge University Press, 2008.

[16] D. Annaratone, "Pressure vessel design", Springer, 2007.

[17] S. Timoshenko, "Strength of material part 2, advanced theory and problems", 3rd Edition, D. Van Nostrand Company Inc., Princeton, NJ, 1956.

[18] S. S. Al-Rushudi, "Finite Element Versus Boundary Element Analysis of Two-Dimensional Coupled Thermoelasticity", Ph.D. thesis, Mechanical Engineering Dept., Cranfield Institute of Technology, Cranfield, 1991.

[19] P. P. Poworoznek, "Elastic-plastic behavior of a cylinder subject to mechanical and thermal loads", M.Sc. thesis, Rensselaer Polytechnic Institute, Hartford, CT, 2008.

[20] Status Report for Advanced Nuclear Reactor Designs Report 108 (VVER-1200(V-491)).

[21] B. Yamaji and A. Aszódi, "CFD analysis of coolant mixing in VVER-1000 pressure vessel".

[22] ANSYS version 11.0; 2007 